\title{
Development and Validation of a Clinical Predictive Model for Bacterial Infection in Hepatitis B Virus- Related Acute-on-Chronic Liver Failure
}

\author{
Zhongwei Zhang · Ke Ma · Zhongyuan Yang • Qiuyu Cheng • \\ Xue $\mathrm{Hu} \cdot$ Meiqi Liu · Yunhui Liu · Tingting Liu • Meng Zhang • \\ Xiaoping Luo • Tao Chen • Qin Ning
}

Received: March 5, 2021 / Accepted: April 30, 2021 / Published online: May 15, 2021

(C) The Author(s) 2021

\begin{abstract}
Introduction: Bacterial infection is one of the most frequent complications in hepatitis B virus-related acute-on-chronic liver failure (HBV-ACLF), which leads to high mortality. However, a predictive model for bacterial infection in HBV-ACLF has not been well established. This study aimed to establish and validate a predictive model for bacterial infection in two independent patient cohorts.

Methods: Admission data from a prospective cohort of patients with HBV-ACLF without bacterial infection on admission was used for derivation. Bacterial infection development
\end{abstract}

Supplementary Information The online version contains supplementary material available at https:// doi.org/10.1007/s40121-021-00454-2.

Z. Zhang · K. Ma . Z. Yang - Q. Cheng . X. Hu M. Liu - Y. Liu · T. Liu · M. Zhang · T. Chen ( $₫)$. Q. Ning ( $\square)$

Department and Institute of Infectious Disease, Tongji Hospital, Tongji Medical College, Huazhong University of Science and Technology, 1095, Jiefang Avenue, Wuhan 430030, Hubei, China e-mail: chentao_tjh@vip.sina.com

Q. Ning

e-mail: qning@vip.sina.com

X. Luo

Department of Pediatrics, Tongji Hospital, Tongji Medical College, Huazhong University of Science and Technology, 1095, Jiefang Avenue, Wuhan 430030, Hubei, China from day 3 to 7 of admission was captured. Independent predictors of bacterial infection development on multivariate logistic regression were used to develop the predictive model. External validation was performed on a separate retrospective cohort.

Results: A total of 377 patients were enrolled into the derivation cohort, including 88 patients (23.3\%) who developed bacterial infection from day 3 to 7 of admission. On multivariate regression analysis, admission serum globulin (OR 0.862, 95\% CI 0.822-0.904; $P<0.001$ ), interleukin-6 (OR 1.023, 95\% CI 1.006-1.040; $P=0.009)$, and C-reactive protein (OR 1.123, 95\% CI 1.081-1.166; $P<0.001$ ) levels were independent predictors for the bacterial infection development, which were adopted as parameters of the predictive model (GIC). In the derivation cohort, the area under the curve (AUC) of GIC was 0.861 (95\% CI 0.821-0.902). A total of 230 patients were enrolled into the validation cohort, including 57 patients (24.8\%) who developed bacterial infection from day 3 to 7 of admission, and the AUC of GIC was 0.836 (95\% CI 0.782-0.881). The Hosmer-Lemeshow test showed a good calibration performance of the predictive model in the two cohorts $(P=0.199, P=0.746)$. Decision curve analysis confirmed the clinical utility of the predictive model.

Conclusion: GIC was established and validated for the prediction of bacterial infection development in HBV-ACLF, which may provide a 
potential auxiliary solution for the primary complication of HBV-ACLF.

Keywords: Acute-on-chronic liver failure; Hepatitis B virus; Bacterial infection; Risk factor; Predictive model

\section{Key Summary Points}

\section{Why carry out this study?}

Bacterial infection can lead to high mortality in HBV-ACLF.

To establish and validate a predictive model for bacterial infection in HBVACLF.

\section{What was learned from the study?}

Serum globulin, interleukin-6, and C-reactive protein levels are independent predictors of bacterial infection development in HBV-ACLF.

The predictive model shows good discrimination, calibration, and clinical utility, which may provide an auxiliary solution of bacterial infection in HBVACLF.

\section{DIGITAL FEATURES}

This article is published with digital features, including a summary slide, to facilitate understanding of the article. To view digital features for this article go to https://doi.org/10.6084/ m9.figshare.14509935.

\section{INTRODUCTION}

Bacterial infection is one of the most frequent complications in acute-on-chronic liver failure (ACLF) and it primarily triggers consequent hepatorenal syndrome (HRS), hepatic encephalopathy (HE), and gastrointestinal bleeding, which generally leads to elevated mortality [1]. Among bacterial infections, spontaneous bacterial peritonitis (SBP), respiratory infection, and urinary tract infection (UTI) are the major types of bacterial infection in ACLF $[2,3]$. Early diagnosis and timely control of bacterial infection would significantly decrease the mortality of ACLF $[4,5]$. However, bacterial infection in ACLF is largely undetected in clinical settings because of mild or even lack of symptoms at earlier stages.

Currently, bacterial infection is generally diagnosed on the basis of clinical features, laboratory tests, and imaging examinations. Some conventional biomarkers, such as C-reactive protein (CRP) and procalcitonin (PCT), have been shown to be reliable for diagnosing bacterial infection in patients with liver cirrhosis [6]. However, the predictive parameters or models for bacterial infection in ACLF have not been clearly identified.

The systemic inflammatory response plays an important role in the onset and progression of bacterial infection in ACLF [7]. Although inflammatory mediators are potential early biomarkers for bacterial infection, they have not yet been investigated as satisfactory parameters in ACLF. Serum interleukin-6 (IL-6) levels have been identified for rapid detection of bacterial sepsis in cirrhosis with a sensitivity of $97.4 \%$ and a specificity of $80.6 \%$ [8]. Moreover, a predictive model with CRP, interleukin-8 (IL8 ), and soluble interleukin-2 receptor (sIL-2R) showed a sensitivity of $78.0 \%$ and specificity of 93.2\% for early sepsis and $90.1 \%$ and $97.8 \%$ for late-onset sepsis [9]. Accumulating evidence indicates that the aforementioned inflammatory variables could be used as predictors of bacterial infection development in ACLF. In addition, the leading cause of ACLF is an acute exacerbation of hepatitis B virus (HBV) infection, which accounts for more than $80 \%$ of all cases in China. ACLF caused by HBV is known as HBV-related ACLF (HBV-ACLF) [10, 11].

In the present study, serum concentrations of eight inflammatory parameters, namely CRP, PCT, interleukin-1 $\beta$ (IL-1 $\beta$ ), sIL-2R, IL-6, IL-8, interleukin-10 (IL-10), and tumor necrosis factor alpha $(\mathrm{TNF} \alpha)$, were evaluated during the onset and progression of bacterial infection in HBV-ACLF. Moreover, the predictive model for 
bacterial infection development in ACLF was established and validated, which provides a potential auxiliary solution for the primary complication of HBV-ACLF.

\section{METHODS}

\section{Patients}

A total of 665 patients with HBV-ACLF were prospectively screened between July 1, 2018 and June 30, 2020 at the Department of Infectious Disease, Tongji Hospital, Tongji Medical College, Huazhong University of Science and Technology. A total of 288 patients were excluded and 377 patients were enrolled into the derivation cohort, which included 88 patients who developed bacterial infection from day 3 to 7 of admission and 289 patients who never developed bacterial infection during hospitalization. A total of 588 patients with HBV-ACLF were retrospectively screened between January 1, 2016 and May 31, 2018 at the same center. A total of 358 patients were excluded and 230 patients were enrolled into the validation cohort, which included 57 patients who developed bacterial infection from day 3 to 7 of admission and 173 patients who never developed bacterial infection during hospitalization (Supplementary Fig. 1).

Patients in the prospective cohort were from a secondary study of a clinical trial (NCT03362632); they were informed of the process of the study and gave consent for inclusion in the study (as well as the primary trial). Patients in the retrospective cohort were not informed of the process of the study, but this study protocol was approved by the Ethics Committee of Tongji Hospital. Data of all patients were acquired from the electronic medical records system and analyzed anonymously according to the Declaration of Helsinki of 1975 , as revised in 2008.

The diagnostic criteria of ACLF were based on the consensus definition of the Asian Pacific Association for the Study of the Liver (APASL) 2014 as follows: patients develop an acute hepatic insult manifesting as jaundice [serum bilirubin $\geq 5 \mathrm{mg} / \mathrm{dL} \quad(85 \mu \mathrm{mol} / \mathrm{L})] \quad$ and coagulopathy [international normalized ratio (INR) $\geq 1.5$ or prothrombin activity $<40 \%$ ] complicated within 4 weeks by clinical ascites and/or encephalopathy and with previously diagnosed or undiagnosed chronic liver disease/cirrhosis [12]. The enrollment criteria for patients with chronic hepatitis B were according to the 2015 APASL guidelines: chronic inflammatory disease of the liver caused by persistent infection with HBV (HBsAg seropositive status at 6 months or beyond) [13].

Patients were excluded if they fulfilled one or more of the following criteria: evidence of bacterial infection on admission, bacterial infection developed within 2 days or over 7 days after admission, fungal or viral infections, hepatitis with other etiologies (hepatitis $\mathrm{C}$ or autoimmune liver disease), hepatocellular carcinoma or other malignancies, liver transplantation, pregnancy, the presence of preterminal comorbidities (heart disease New York Heart Association III-IV, severe chronic obstructive pulmonary disease, chronic renal failure with creatinine $>1.5 \mathrm{mg} / \mathrm{dL}$ ), age less than 18 years, human immunodeficiency virus infection, and any other type of immunodeficiency.

Cirrhosis was diagnosed on the basis of previous liver biopsy results, decompensation history, endoscopy and radiological evidence of portal hypertension and/or liver nodularity. Ascites was confirmed by abdominal imaging and paracentesis. Gastrointestinal bleeding was diagnosed on the basis of the presence of blood in the stool or vomit. HE was defined as neuropsychiatric abnormalities diagnosed by the West Haven criteria [14]. HRS was diagnosed according to the International Club of Ascites (ICA)-AKI criteria [15]. The model for end-stage liver disease (MELD), MELD-sodium, and the APASL-ACLF research consortium (AARC) scores were calculated to determine the severity of ACLF [12, 16]. Patient demographics, clinical and laboratory data, and bacterial infection were recorded after enrollment. The end point of the study was set as death within 90 days. After admission, the symptoms and signs of patients were closely monitored, and laboratory tests and imaging examinations were performed every 3-7 days depending on patients' 
individual clinical situations. Patients returned for follow-up every 2-4 weeks after discharge.

\section{Criteria Related to Bacterial Infection}

Bacterial infection was diagnosed through a combination of clinical features, laboratory tests, and imaging findings. The criteria for the diagnosis of bacterial infection were as follows: (a) SBP: polymorphonuclear (PMN) cell count in ascitic fluid $\geq 250 / \mathrm{mm}^{3}$ in the absence of an intra-abdominal source of infection. (b) Pneumonia: clinical signs of bacterial infection and new infiltrates on chest X-ray or computed tomography. (c) UTI: abnormal urinary sediment (> 10 leukocytes/field) and positive urinary culture or uncountable leukocytes per field if there was a negative urinary culture. (d) Spontaneous bacteremia: positive blood culture and no cause of bacteremia. (e) Cholangitis: cholestasis, right upper quadrant pain and/or jaundice and radiological evidence of biliary obstruction. (f) Other bacterial infections: intra-abdominal bacterial infection or Clostridium difficile-associated colitis [2].

\section{Treatment}

During hospitalization, all patients received oral anti-HBV drugs (nucleoside analogues) and routine supportive treatment, including bed rest, adequate nutritional support, intensive care, and monitoring. Complications including ascites, HE, HRS, and gastrointestinal bleeding were closely monitored and managed immediately. Only patients having indications or meeting the diagnostic criteria of bacterial infection were treated with antibiotics. The empirical antibiotic treatment was prescribed and changed by the attending physicians according to antibiotic susceptibility tests and clinical evolution. All decisions regarding the management of patients were made by the attending clinicians according to the patients' conditions and standard recommendations $[6,17]$.

\section{Statistical Analysis}

Categorical variables were indicated as numbers (proportions) and were compared by the chisquare test or Fisher's exact test. Continuous variables were shown as the means \pm standard deviations for normal distribution and medians with interquartile ranges (P25-P75) for nonnormal distribution, which were compared by the Student's $t$ test and the Mann-Whitney $U$ test, respectively. Univariate and multivariate logistic regression analyses were performed to investigate risk factors for the development of bacterial infection. Analysis of receiver operating characteristic (ROC) curves was used to calculate the area under the curve (AUC), and Youden index was used to determine the suggested cutoff value. For the cutoff value, the discriminative accuracy was reported in terms of sensitivity, specificity, positive predictive value, and negative predictive value. The Hosmer-Lemeshow test was used to assess the calibration of predictive model, with lower $\chi^{2}$ and higher $P$ values indicating better calibration. Decision curve analysis (DCA) was used to assess the clinical utility of the predictive model. All data were analyzed with IBM SPSS Statistics software (version 23.0, Chicago, USA), MedCalc software (version 11.4, Ostend, Belgium), and $\mathrm{R}$ statistical analysis software (version 4.0.4, Vienna, Austria), and $P<0.05$ (two-sided) was considered statistically significant.

\section{RESULTS}

\section{Characteristics of Patients in Derivation and Validation Cohorts}

In the derivation cohort, a total of 88 patients (23.3\%) developed bacterial infection from day 3 to 7 of admission: 43 with pneumonia, 29 with SBP, 8 with UTI, 5 with bacteremia, and 3 with other infections. In the validation cohort, a total of 57 patients $(24.8 \%)$ developed bacterial infection from day 3 to 7 of admission: 27 with pneumonia, 20 with SBP, 5 with UTI, 3 with bacteremia, and 2 with other infections (Table 1). In the derivation cohort, positive culture results were detected in 18 specimens, 
Table 1 Characteristics of patients in the derivation and validation cohorts

\begin{tabular}{|c|c|c|c|}
\hline & Derivation cohort $(n=377)$ & Validation cohort $(n=230)$ & $P$ value \\
\hline Age (years) & $47 \pm 12$ & $45 \pm 11$ & 0.038 \\
\hline Male, $n(\%)$ & $305(80.9)$ & $205(89.1)$ & 0.113 \\
\hline Heart beats (bpm) & $81(76-90)$ & $82(76-90)$ & 0.882 \\
\hline MAP $(\mathrm{mmHg})$ & $91(86-99)$ & $92(86-96)$ & 0.811 \\
\hline Cirrhosis, $n(\%)$ & $218(57.8)$ & $124(53.9)$ & 0.569 \\
\hline \multicolumn{4}{|l|}{ Precipitating event } \\
\hline HBV reactivation, $n(\%)$ & $344(91.2)$ & $221(96.1)$ & 0.152 \\
\hline Spontaneous reactivation, $n(\%)$ & $250(66.3)$ & $174(75.7)$ & 0.119 \\
\hline NUC cessation, $n(\%)$ & $74(19.6)$ & $40(17.4)$ & 0.585 \\
\hline NUC resistance, $n(\%)$ & $20(5.3)$ & $7(3.0)$ & 0.721 \\
\hline Others, $n(\%)$ & $33(8.8)$ & $9(3.9)$ & 0.152 \\
\hline \multicolumn{4}{|l|}{ Complications } \\
\hline Ascites, $n(\%)$ & $275(73.0)$ & $150(65.2)$ & 0.221 \\
\hline $\mathrm{HE}, n(\%)$ & $40(10.6)$ & $32(13.9)$ & 0.521 \\
\hline $\mathrm{HRS}, n(\%)$ & $11(2.9)$ & $10(4.3)$ & 0.700 \\
\hline GI bleeding, $n(\%)$ & $12(3.2)$ & $15(6.5)$ & 0.331 \\
\hline Paracentesis, $n$ (\%) & $44(11.7)$ & $24(10.3)$ & 0.651 \\
\hline Urethral catheterization, $n(\%)$ & $24(6.4)$ & $18(7.8)$ & 0.579 \\
\hline Bacterial infection, $n(\%)$ & $88(23.3)$ & $57(24.8)$ & 0.741 \\
\hline Pneumonia, $n(\%)$ & $43(11.4)$ & $27(11.7)$ & 0.825 \\
\hline SBP, $n(\%)$ & $29(7.7)$ & $20(8.7)$ & 0.800 \\
\hline UTI, $n(\%)$ & $8(2.1)$ & $5(2.2)$ & \\
\hline Bacteremia, $n(\%)$ & $5(1.3)$ & $3(1.3)$ & \\
\hline Others, $n(\%)$ & $3(0.8)$ & $2(0.9)$ & \\
\hline \multicolumn{4}{|l|}{ Laboratory tests } \\
\hline Leukocyte count $\left(\times 10^{9} / \mathrm{L}\right)$ & $5.51(4.12-6.99)$ & $5.82(4.34-7.26)$ & 0.258 \\
\hline Neutrophil count $\left(\times 10^{9} / \mathrm{L}\right)$ & $3.50(2.65-4.87)$ & $3.88(2.74-4.98)$ & 0.301 \\
\hline Lymphocyte count $\left(\times 10^{9} / \mathrm{L}\right)$ & $1.06(0.78-1.46)$ & $1.15(0.85-1.51)$ & 0.074 \\
\hline Monocyte count $\left(\times 10^{9} / \mathrm{L}\right)$ & $0.59(0.40-0.80)$ & $0.58(0.43-0.83)$ & 0.831 \\
\hline Platelet count $\left(\times 10^{9} / \mathrm{L}\right)$ & $91(64-126)$ & $95(68-129)$ & 0.339 \\
\hline Hemoglobin $(\mathrm{g} / \mathrm{L})$ & $120 \pm 22$ & $123 \pm 20$ & 0.098 \\
\hline $\operatorname{ALT}(\mathrm{U} / \mathrm{L})$ & $220(76-568)$ & $285(97-647)$ & 0.087 \\
\hline AST (U/L) & $185(88-436)$ & $206(116-460)$ & 0.081 \\
\hline
\end{tabular}


Table 1 continued

\begin{tabular}{|c|c|c|c|}
\hline & Derivation cohort $(n=377)$ & Validation cohort $(n=230)$ & $P$ value \\
\hline Albumin $(\mathrm{g} / \mathrm{L})$ & $32.7 \pm 4.6$ & $32.0 \pm 4.4$ & 0.001 \\
\hline Globulin $(\mathrm{g} / \mathrm{L})$ & $28.6(23.9-33.4)$ & $26.8(22.8-31.2)$ & 0.003 \\
\hline Total bilirubin $(\mu \mathrm{mol} / \mathrm{L})$ & $264.9(188.6-375.4)$ & $291.6(215.0-389.6)$ & 0.042 \\
\hline $\mathrm{LDH}(\mathrm{U} / \mathrm{L})$ & $240(199-300)$ & $234(193-278)$ & 0.075 \\
\hline Creatinine $(\mu \mathrm{mol} / \mathrm{L})$ & $62(52-76)$ & $63(54-75)$ & 0.626 \\
\hline Sodium $(\mathrm{mmol} / \mathrm{L})$ & $136.4(133.7-138.4)$ & $136.5(133.7-138.3)$ & 0.970 \\
\hline Ammonia $(\mu \mathrm{mol} / \mathrm{L})$ & $63(48-86)$ & $66(50-86)$ & 0.578 \\
\hline INR & $1.93(1.65-2.35)$ & $2.38(1.84-2.76)$ & $<0.001$ \\
\hline HBeAg positive, $n$ (\%) & $121(32.1)$ & $92(40.0)$ & 0.239 \\
\hline HBV DNA $\left(\log _{10} \mathrm{IU} / \mathrm{mL}\right)$ & $5.13(4.49-6.54)$ & $4.80(3.82-6.31)$ & 0.035 \\
\hline Alpha fetoprotein (ng/ml) & $68.1(18.8-226.0)$ & $91.4(27.1-266.0)$ & 0.032 \\
\hline Lactate $(\mathrm{mmol} / \mathrm{L})$ & $2.16(1.62-2.48)$ & $1.93(1.59-2.33)$ & 0.004 \\
\hline Ferritin $(\mu \mathrm{g} / \mathrm{L})$ & $1673.5(975.6-2293.5)$ & $1556.4(756.4-2193.8)$ & 0.068 \\
\hline $\mathrm{CRP}(\mathrm{mg} / \mathrm{L})$ & $9.5(6.0-14.3)$ & $9.8(6.1-14.5)$ & 0.590 \\
\hline PCT (ng/mL) & $0.38(0.28-0.52)$ & $0.41(0.28-0.50)$ & 0.734 \\
\hline $\mathrm{IL}-1 \beta(\mathrm{pg} / \mathrm{mL})$ & $8.5(5.0-18.0)$ & $6.9(5.0-16.6)$ & 0.063 \\
\hline sIL-2R (U/mL) & $1295(962-1887)$ & $1401(1003-1697)$ & 0.833 \\
\hline IL-6 (pg/mL) & $17.6(12.6-27.2)$ & $19.9(12.1-33.8)$ & 0.180 \\
\hline IL-8 (pg/mL) & $179.0(79.0-359.0)$ & $167.5(77.3-315.5)$ & 0.526 \\
\hline IL-10 (pg/mL) & $8.2(5.3-12.9)$ & $8.6(6.2-12.8)$ & 0.907 \\
\hline $\mathrm{TNF} \alpha(\mathrm{pg} / \mathrm{mL})$ & $17.2(12.8-24.7)$ & $17.2(13.4-25.4)$ & 0.844 \\
\hline MELD score & $21(19-24)$ & $23(20-27)$ & $<0.001$ \\
\hline MELD-sodium score & $23(20-26)$ & $25(22-29)$ & $<0.001$ \\
\hline AARC score & $8(7-9)$ & $8(7-10)$ & 0.002 \\
\hline 30-day mortality (\%) & 13.0 & 13.9 & 0.836 \\
\hline 90-day mortality (\%) & 24.4 & 25.2 & 0.869 \\
\hline
\end{tabular}

Data are expressed as means \pm standard deviations or as medians with interquartile ranges or as frequencies and percentages $M A P$ mean arterial pressure, NUC nucleoside analogue, $H E$ hepatic encephalopathy, HRS hepatorenal syndrome, GI gastrointestinal, $S B P$ spontaneous bacterial peritonitis, $U T I$ urinary tract infection, $A L T$ alanine aminotransaminase, $A S T$ aspartate aminotransaminase, $L D H$ lactate dehydrogenase, $I N R$ international normalized ratio, $M E L D$ model for end-stage liver disease, AARC Asian Pacific Association for the Study of the Liver-ACLF research consortium 
including gram-negative bacteria in 11 specimens $(61.1 \%)$ and gram-positive bacteria in 7 isolates $(38.9 \%)$. In the validation cohort, positive culture results were detected in 13 specimens, including gram-negative bacteria in 8 specimens $(61.5 \%)$ and gram-positive bacteria in 5 isolates $(38.5 \%)$ (Supplementary Table 1). The proportions of multidrug-resistant bacteria in culture-positive infections in the derivation and validation cohorts were $16.7 \%$ and $15.4 \%$, respectively.

In the two cohorts, the majority of patients had HBV reactivation as the cause of ACLF owing to spontaneous reactivation, nucleoside analogue (NUC) cessation, or NUC resistance. There was no significant difference in gender distribution, precipitating events, presence of cirrhosis and complications, frequency of paracentesis and urethral catheterization, types of bacterial infection, peripheral blood parameters, serum creatinine, sodium, ammonia, ferritin, CRP, PCT, inflammatory cytokines levels, as well as 30-day and 90-day mortality between the two cohorts. Serum total bilirubin, alpha fetoprotein, INR, as well as MELD, MELDsodium, and AARC scores in the derivation cohort were significantly lower than those in the validation cohort. Meanwhile, age, serum globulin, albumin, lactate, and HBV-DNA levels were significantly higher in the derivation

a

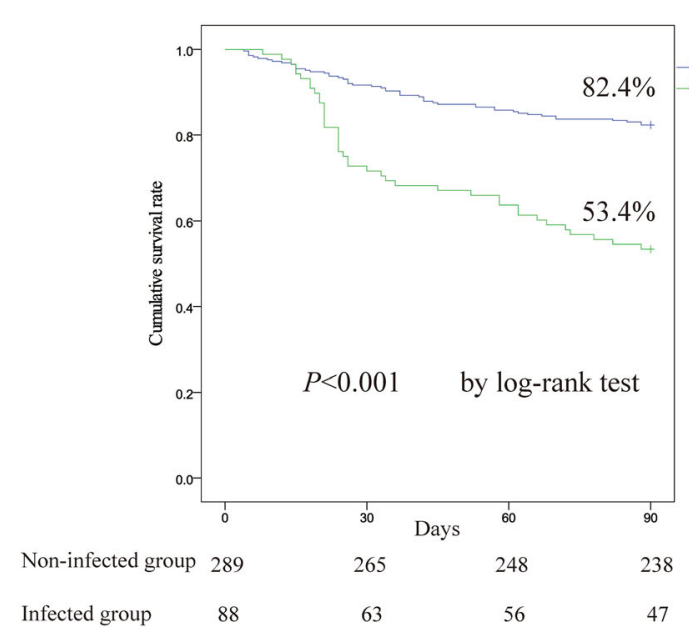

cohort compared with the validation cohort (Table 1).

Patients were divided into the non-infected and infected groups according to the development of bacterial infection. The 90-day cumulative survival rates of the non-infected group were significantly higher than those of the infected group in the derivation $(82.4 \%$ vs. $53.4 \%, \quad P<0.001)$ and validation cohorts (83.8\% vs. $47.4 \%, P<0.001$ ) (Fig. 1 ).

\section{Baseline Characteristics of Patients Who Developed Bacterial Infection in Derivation Cohort}

Compared with patients in the non-infected group, patients in the infected group showed a higher frequency of ascites, HE, and HRS, as well as higher neutrophil count, monocyte count, serum total bilirubin, INR, CRP, IL-1 $\beta$, sIL-2R, IL-6, IL-10, MELD, MELD-sodium, AARC scores, and lower platelet count, hemoglobin, globulin protein, alpha fetoprotein, and HBV-DNA levels (Table 2).

\section{Univariate and Multivariate Risk Analysis for Bacterial Infection Development}

By univariate analysis, the presence of cirrhosis, ascites, gastrointestinal bleeding, HE, HRS,

b

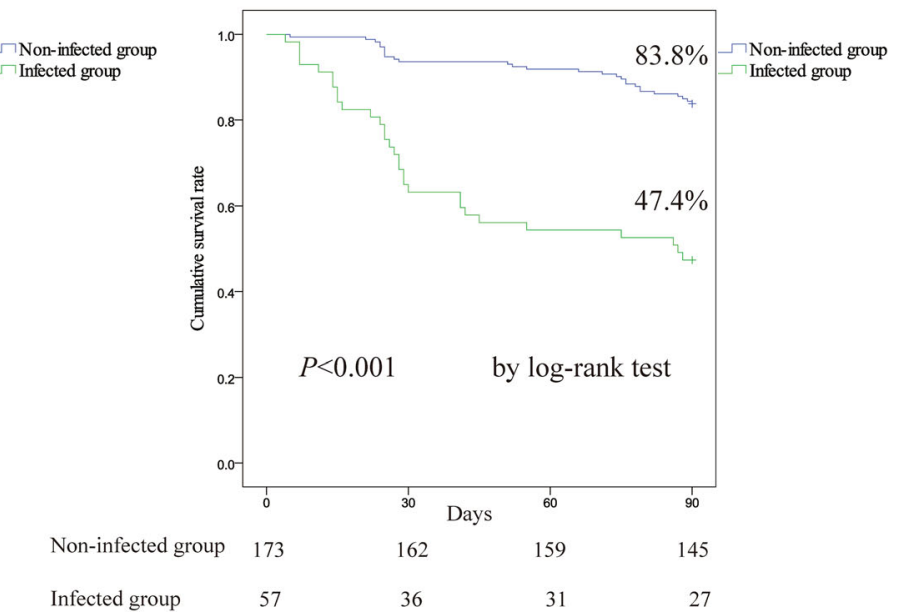

Fig. 1 Survival log-rank curve at 90 days of patients in the infected and non-infected groups in the derivation (a) and validation $(\mathbf{b})$ cohorts 
Table 2 Baseline characteristics of patients categorized according to the development of bacterial infection in the derivation cohort

\begin{tabular}{|c|c|c|c|}
\hline & Non-infected group $(n=289)$ & Infected group $(n=88)$ & $P$ value \\
\hline Age (years) & $46 \pm 12$ & $49 \pm 12$ & 0.074 \\
\hline Male, $n(\%)$ & $232(80.3)$ & $73(83.0)$ & 0.585 \\
\hline Heart beats (bpm) & $81(75-90)$ & $81(77-92)$ & 0.559 \\
\hline MAP (mmHg) & $91(85-99)$ & $90(86-98)$ & 0.646 \\
\hline Cirrhosis, $n$ (\%) & $159(55.0)$ & $59(67.0)$ & 0.082 \\
\hline \multicolumn{4}{|l|}{ Complications } \\
\hline Ascites, $n(\%)$ & $201(69.6)$ & $74(84.1)$ & 0.019 \\
\hline HE, $n(\%)$ & $24(8.3)$ & $16(18.2)$ & 0.036 \\
\hline HRS, $n(\%)$ & $4(1.4)$ & $7(8.0)$ & 0.035 \\
\hline GI bleeding, $n(\%)$ & $6(2.1)$ & $6(6.8)$ & 0.170 \\
\hline Paracentesis, $n$ (\%) & $30(10.4)$ & $14(15.9)$ & 0.207 \\
\hline Urethral catheterization, $n(\%)$ & $17(5.9)$ & $7(8.0)$ & 0.579 \\
\hline \multicolumn{4}{|l|}{ Laboratory tests } \\
\hline Leukocyte count $\left(\times 10^{9} / \mathrm{L}\right)$ & $5.34(4.01-6.97)$ & $5.95(4.71-7.50)$ & 0.075 \\
\hline Neutrophil count $\left(\times 10^{9} / \mathrm{L}\right)$ & $3.48(2.55-4.72)$ & $3.72(2.76-5.63)$ & 0.044 \\
\hline Lymphocyte count $\left(\times 10^{9} / \mathrm{L}\right)$ & $1.08(0.82-1.47)$ & $0.99(0.70-1.41)$ & 0.094 \\
\hline Monocyte count $\left(\times 10^{9} / \mathrm{L}\right)$ & $0.57(0.39-0.77)$ & $0.70(0.46-0.88)$ & 0.012 \\
\hline Platelet count $\left(\times 10^{9} / \mathrm{L}\right)$ & $92(68-132)$ & $82(54-118)$ & 0.036 \\
\hline Hemoglobin $(\mathrm{g} / \mathrm{L})$ & $123 \pm 21$ & $114 \pm 24$ & 0.001 \\
\hline $\operatorname{ALT}(\mathrm{U} / \mathrm{L})$ & $235(83-589)$ & $163(58-553)$ & 0.213 \\
\hline AST (U/L) & $191(90-431)$ & $154(74-488)$ & 0.447 \\
\hline Albumin $(\mathrm{g} / \mathrm{L})$ & $33.3 \pm 4.6$ & $32.9 \pm 4.3$ & 0.404 \\
\hline Globulin $(\mathrm{g} / \mathrm{L})$ & $29.8(25.9-35.0)$ & $24.5(19.7-28.1)$ & $<0.001$ \\
\hline Total bilirubin $(\mu \mathrm{mol} / \mathrm{L})$ & $254.0(184.0-353.3)$ & $320.4(193.6-445.5)$ & 0.001 \\
\hline $\mathrm{LDH}(\mathrm{U} / \mathrm{L})$ & $227(196-290)$ & $254(214-325)$ & 0.052 \\
\hline Creatinine $(\mu \mathrm{mol} / \mathrm{L})$ & $62(52-74)$ & $64(51-81)$ & 0.290 \\
\hline Sodium $(\mathrm{mmol} / \mathrm{L})$ & $136.5(133.8-138.4)$ & $136.3(132.8-138.6)$ & 0.705 \\
\hline Ammonia $(\mu \mathrm{mol} / \mathrm{L})$ & $64(49-91)$ & $62(45-77)$ & 0.162 \\
\hline INR & $1.87(1.64-2.25)$ & $2.19(1.72-2.68)$ & 0.006 \\
\hline HBeAg positive, $n$ (\%) & $101(34.9)$ & $20(22.7)$ & 0.061 \\
\hline HBV DNA $\left(\log _{10} \mathrm{IU} / \mathrm{mL}\right)$ & $5.10(4.52-6.54)$ & $4.70(3.59-5.79)$ & 0.017 \\
\hline Alpha fetoprotein (ng/ml) & $81.5(23.9-260.0)$ & $36.9(8.4-134.7)$ & 0.001 \\
\hline
\end{tabular}


Table 2 continued

\begin{tabular}{lllr}
\hline & Non-infected group $(\boldsymbol{n}=\mathbf{2 8 9})$ & Infected group $(\boldsymbol{n}=\mathbf{8 8})$ & $\boldsymbol{P}$ value \\
\hline Lactate $(\mathrm{mmol} / \mathrm{L})$ & $2.15(1.62-2.44)$ & $2.21(1.72-2.66)$ & 0.085 \\
Ferritin $(\mu \mathrm{g} / \mathrm{L})$ & $1640.6(921.0-2275.5)$ & $1762.7(1003.5-2479.9)$ & 0.274 \\
CRP $(\mathrm{mg} / \mathrm{L})$ & $8.4(5.6-11.8)$ & $14.4(11.1-21.7)$ & $<0.001$ \\
PCT $(\mathrm{ng} / \mathrm{mL})$ & $0.38(0.26-0.51)$ & $0.42(0.28-0.54)$ & 0.260 \\
IL-1 $\beta(\mathrm{pg} / \mathrm{mL})$ & $8.9(5.2-18.6)$ & $7.3(5.0-16.7)$ & 0.026 \\
sIL-2R $(\mathrm{U} / \mathrm{mL})$ & $1250(892-1600)$ & $1465(1131-2037)$ & 0.007 \\
IL-6 $(\mathrm{pg} / \mathrm{mL})$ & $15.8(9.9-23.2)$ & $16.2(19.2-39.2)$ & $<0.001$ \\
IL-8 $(\mathrm{pg} / \mathrm{mL})$ & $187.2(78.7-345.0)$ & $9.5(6.4-15.8)$ & 0.975 \\
IL-10 $(\mathrm{pg} / \mathrm{mL})$ & $7.8(5.2-12.6)$ & $18.0(13.1-24.7)$ & 0.008 \\
TNF $\alpha(\mathrm{pg} / \mathrm{mL})$ & $17.0(12.6-25.0)$ & $23(19-27)$ & 0.804 \\
MELD score & $20(18-24)$ & $24(21-30)$ & $<0.001$ \\
MELD-sodium score & $23(20-26)$ & $9(7-10)$ & $<0.001$ \\
AARC score & $8(7-9)$ & 0.001 \\
\hline
\end{tabular}

$M A P$ mean arterial pressure, $H E$ hepatic encephalopathy, $H R S$ hepatorenal syndrome, GI gastrointestinal, $A L T$ alanine aminotransaminase, $A S T$ aspartate aminotransaminase, $L D H$ lactate dehydrogenase, $I N R$ international normalized ratio, MELD model for end-stage liver disease, AARC Asian Pacific Association for the Study of the Liver-ACLF research consortium

monocyte count, serum total bilirubin, creatinine, INR, CRP, sIL-2R, IL-6, IL-10, and lower platelet count, serum hemoglobin, and globulin levels were identified as risk factors for the bacterial infection development. Of these parameters, serum globulin (OR 0.862, 95\% CI 0.822-0.904; $P<0.001$ ), IL-6 (OR 1.023, 95\% CI 1.006-1.040; $P=0.009$ ), and CRP (OR 1.123, 95\% CI 1.081-1.166; $P<0.001$ ) levels were identified as independent predictors for bacterial infection development on multivariate analysis (Table 3).

\section{Predictive Model of Bacterial Infection Development in Patients with HBV-ACLF}

On the basis of the multivariate analysis, we established an equation for the predictive model of bacterial infection development in HBV-ACLF: $\quad$ GIC $\quad$ score $=0.803+0.116 \times($ $\mathrm{CRP})+0.022 \times($ IL-6) $-0.148 \times($ globulin $)$.
CRP is expressed in milligrams per liter, IL-6 in picograms per milliliter, and globulin in grams per liter.

The goodness-of-fit $\chi^{2}$ of GIC was 11.053 $(P=0.199)$ in the derivation cohort, and 5.105 $(P=0.746)$ in the validation cohort, which indicated no evidence of poor fit.

In the derivation cohort, the AUC of GIC was 0.861 (95\% CI 0.821-0.902) (Fig. 2a). With a cutoff value of -1.03 , the sensitivity and specificity of GIC were $78.4 \%$ and $83.4 \%$, respectively. The positive predictive value was $59.0 \%$, and the negative predictive value was $92.7 \%$. In the validation cohort, the AUC of GIC was 0.836 (95\% CI 0.782-0.881) (Fig. 2b). With the cutoff value of -1.03 , the sensitivity and specificity of GIC were $75.4 \%$ and $75.1 \%$, respectively. The positive predictive value was $50.0 \%$, and the negative predictive value was $90.3 \%$. When patients were stratified by the GIC score, patients with GIC score of at least -1.03 
Table 3 Univariate and multivariate risk analysis for the development of bacterial infection in patients with HBV-ACLF

\begin{tabular}{|c|c|c|c|c|}
\hline & \multicolumn{2}{|l|}{ Univariate analysis } & \multicolumn{2}{|l|}{ Multivariate analysis } \\
\hline & OR (95\% CI) & $P$ value & OR (95\% CI) & $P$ value \\
\hline Age & $1.018(0.998-1.039)$ & 0.075 & & \\
\hline Male & $1.070(0.590-0.939)$ & 0.824 & & \\
\hline Heart beats & $1.009(0.991-1.028)$ & 0.335 & & \\
\hline MAP & $0.990(0.968-1.013)$ & 0.388 & & \\
\hline Cirrhosis & $1.663(1.008-2.746)$ & 0.047 & & \\
\hline \multicolumn{5}{|l|}{ Complications } \\
\hline Ascites & $2.314(1.240-4.318)$ & 0.008 & & \\
\hline $\mathrm{HE}$ & $2.454(1.238-4.863)$ & 0.010 & & \\
\hline HRS & $4.909(1.518-15.877)$ & 0.008 & & \\
\hline GI bleeding & $2.476(1.245-4.735)$ & 0.036 & & \\
\hline Paracentesis & $1.633(0.823-3.240)$ & 0.160 & & \\
\hline Urethral catheterization & $1.383(0.554-3.451)$ & 0.487 & & \\
\hline \multicolumn{5}{|l|}{ Laboratory tests } \\
\hline Leukocyte count & $1.001(0.962-1.042)$ & 0.958 & & \\
\hline Neutrophil count & $1.016(0.958-1.076)$ & 0.601 & & \\
\hline Lymphocyte count & $0.666(0.407-1.088)$ & 0.104 & & \\
\hline Monocyte count & $2.182(1.097-4.340)$ & 0.026 & & \\
\hline Platelet count & $0.994(0.989-0.999)$ & 0.028 & & \\
\hline Hemoglobin & $0.982(0.972-0.993)$ & 0.001 & & \\
\hline $\mathrm{ALT}$ & $1.000(0.999-1.000)$ & 0.212 & & \\
\hline AST & $1.000(1.000-1.001)$ & 0.730 & & \\
\hline Albumin & $0.978(0.928-1.031)$ & 0.403 & & \\
\hline Globulin & $0.873(0.837-0.911)$ & $<0.001$ & $0.862(0.822-0.904)$ & $<0.001$ \\
\hline Total bilirubin & $1.003(1.001-1.005)$ & 0.001 & & \\
\hline $\mathrm{LDH}$ & $1.002(0.999-1.004)$ & 0.132 & & \\
\hline Creatinine & $1.013(1.004-1.022)$ & 0.003 & & \\
\hline Sodium & $0.976(0.925-1.030)$ & 0.379 & & \\
\hline Ammonia & $0.994(0.986-1.002)$ & 0.139 & & \\
\hline INR & $1.383(1.050-1.823)$ & 0.021 & & \\
\hline HBeAg positive & $0.539(0.309-0.938)$ & 0.059 & & \\
\hline HBV DNA & $0.682(0.572-0.824)$ & 0.054 & & \\
\hline Alpha fetoprotein & $0.999(0.998-1.000)$ & 0.076 & & \\
\hline
\end{tabular}


Table 3 continued

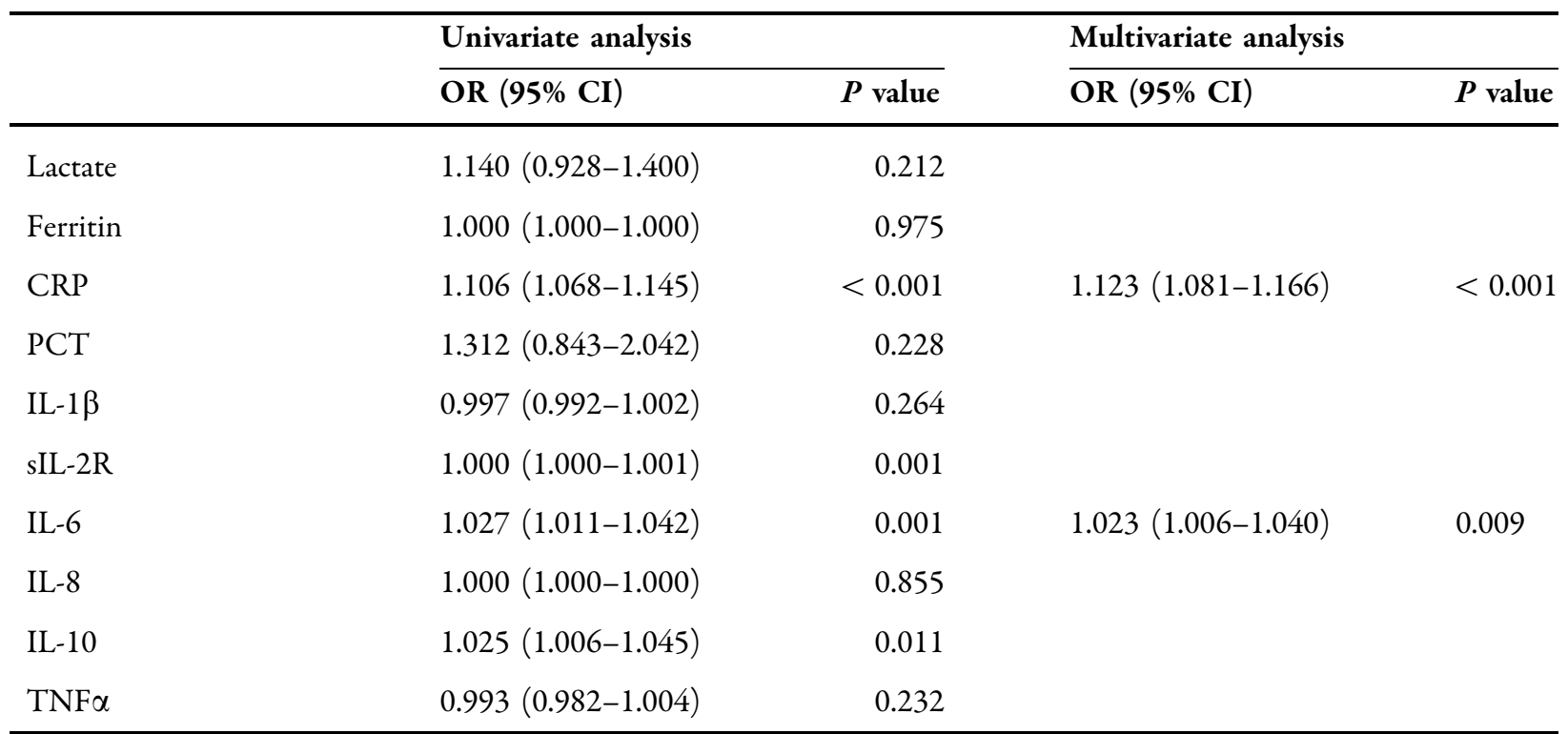

$M A P$ mean arterial pressure, $H E$ hepatic encephalopathy, $H R S$ hepatorenal syndrome, GI gastrointestinal, $A L T$ alanine aminotransaminase, $A S T$ aspartate aminotransaminase, $L D H$ lactate dehydrogenase, $I N R$ international normalized ratio

a

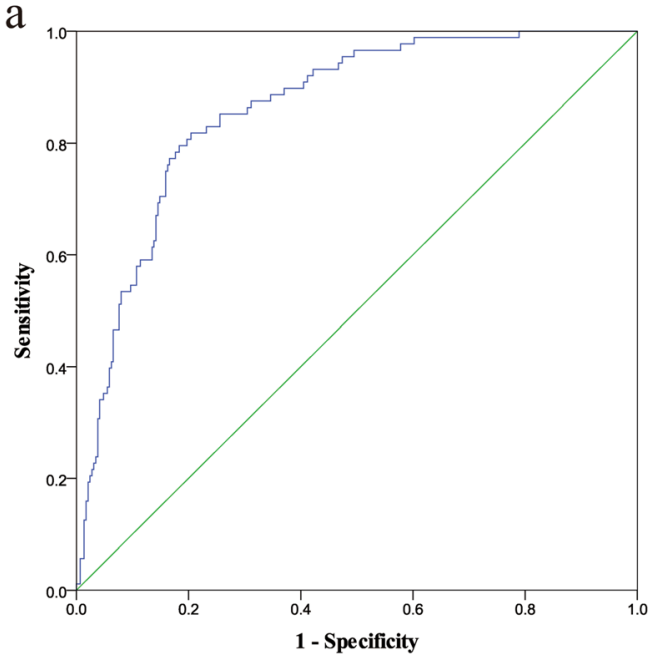

b

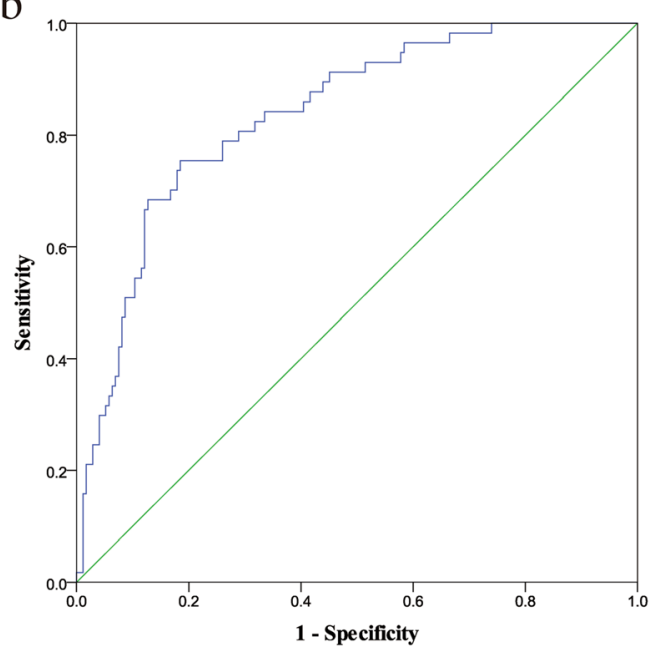

Fig. 2 Receiver operating characteristic curves for the predictive model of bacterial infection development in the derivation (a) and validation (b) cohorts

had significantly higher bacterial infection incidence than patients with GIC score below -1.03 in the derivation $(58.1 \%$ vs. $7.7 \%$, $P<0.001)$ and validation $(49.4 \%$ vs. $9.8 \%$, $P<0.001$ ) cohorts (Fig. 3).

DCA is an appropriate method for assessing predictive models by the net benefit and the range of threshold probabilities. In the present study, the clinical utility of GIC was also assessed by DCA compared with globulin, CRP, and IL-6. The plots indicated that GIC presented a greater net benefit with a wider range of threshold probabilities for predicting bacterial 


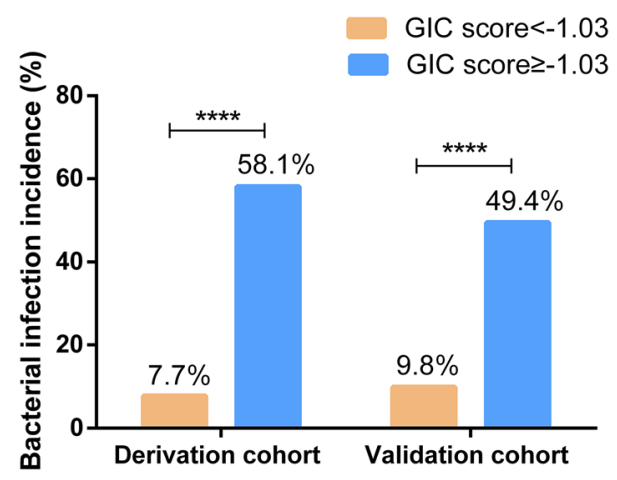

Fig. 3 Incidence of bacterial infection from day 3 to 7 of admission in patients categorized by the cutoff value of GIC in the derivation (a) and validation (b) cohorts

infection development in the derivation (Fig. 4a) and validation cohorts (Fig. 4b).

\section{DISCUSSION}

Accumulating evidence has shown that bacterial infection is one of the most frequent complications and is associated with high mortality in patients with ACLF [18]. In the present study, the short-term mortality of infected group was significantly higher than that of non-infected group. Early diagnosis and immediate treatment of bacterial infection could be a potential strategy to improve the prognosis of these

a

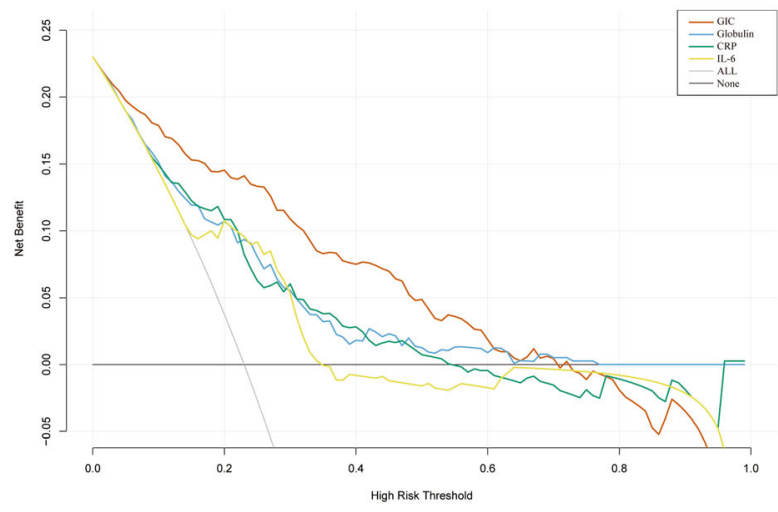

Fig. 4 Decision curve analysis for the predictive model in the derivation (a) and validation (b) cohorts. The $\mathrm{x}$-axis and $y$-axis represent threshold probability and net benefit, respectively. The solid black line of "None" represents the patients. Sepsis is a typical clinical manifestation in ACLF as a consequence of systemic inflammatory response syndrome (SIRS), and new-onset SIRS in the first week is an important determinant of early sepsis, organ failure, and survival [19]. However, in a previous study, 60\% of patients fulfilled the SIRS criteria, and bacterial infection could not be detected [20].

Currently, bacterial infection is generally diagnosed on the basis of clinical features, laboratory tests, and imaging examinations. However, it is easily ignored in some patients who are asymptomatic or lack specific clinical symptoms in ACLF. Bacterial culture is not an effective approach in the diagnosis of bacterial infection because of the low positive culture rate. Some conventional biomarkers have been explored, e.g., the combination of PCT and CRP could improve the diagnostic efficiency of bacterial infection in patients with liver cirrhosis [6]. Moreover, a growing number of studies have attempted to explore novel biomarkers of bacterial infection. Soluble CD163 and presepsin were identified as useful markers for the detection of bacterial infection in patients with cirrhosis [21, 22]. However, most studies have focused on the diagnosis, but not the prediction, of bacterial infection, which limits the early recognition and treatment of ACLF.

Multiple inflammatory mediators contribute to the onset and progression of bacterial

b

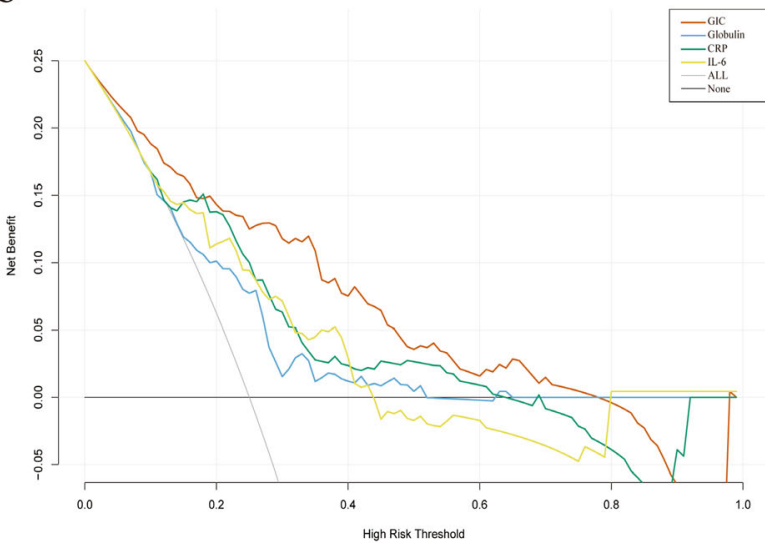

assumption that no patients developed bacterial infection and received no intervention, and the solid gray line of "All" represents the assumption that all patients developed bacterial infection and received interventions 
infection in ACLF, as shown in SIRS [23]. In the present study, we explored the relationship between eight serum inflammatory variables and the occurrence of bacterial infection in patients with ACLF. In the derivation cohort, patients in the infected group had higher serum CRP, IL-1 $\beta$, sIL-2R, IL-6, and IL-10 levels than those in the non-infected group. By multivariate analyses, serum CRP and IL- 6 were identified as independent risk factors for the bacterial infection development in ACLF, which is consistent with previous studies of IL-6 and CRP $[6,8]$. Moreover, low serum globulin levels were also found to be a significant risk factor for the bacterial infection development in ACLF. Serum globulin is correlated with immune system activity and bacterial infection development $[24,25]$. On the basis of this, patients with ACLF and low serum globulin levels were susceptible to pathogenic microorganism invasion, which in turn indicated the predictive value of low serum globulin levels for bacterial infection development.

Although some markers have been explored as having a predictive role for bacterial infection in patients with cirrhosis, such as serum sodium level, Child-Pugh stage C, ascites PMN cell count, or anti-neutrophil cytoplasmic antibody, no exact predictive model has been developed $[26,27]$.

In this present study, the most common type of bacterial infection was pneumonia, followed by SBP and UTI, which was not quite the same as previous studies from Western countries $[28,29]$. Regardless, in combination with GIC, symptoms and signs of infection in the lung, abdominal cavity, and urinary tract, laboratory tests of ascites and urine, and chest imaging examinations were also important for the early detection of bacterial infection in ACLF.

Certain limitations of the present study need to be addressed. First, this predictive model was validated in a retrospective cohort from a single-center study, which should be validated in a multicenter large sample size prospective cohort. Second, the etiology of ACLF in the present study was HBV infection, which is different from other regions, especially in Western countries, where it manifests as alcoholic liver disease or autoimmune liver disease. A further validation of the predictive model in an independent ACLF cohort with various etiologies is suggested.

\section{CONCLUSIONS}

GIC was established and validated for the prediction of bacterial infection development, including serum globulin, IL-6, and CRP, which may facilitate decisions regarding prophylaxis, therapeutic strategies, and surveillance intervals, ultimately improving the prognosis of patients with HBV-ACLF.

\section{ACKNOWLEDGEMENTS}

We thank all the patients and their families involved in this study, as well as numerous doctors and nurses working together to fight against this severe liver disease.

Funding. This study was funded by the National Thirteenth "Five Years" Project in Science and Technology of China (2017ZX10202201, 2018ZX10302-206). The Rapid Service Fees were funded by the authors.

Authorship. All named authors meet the International Committee of Medical Journal Editors (ICMJE) criteria for authorship for this article, take responsibility for the integrity of the work as a whole, and have given their approval for this version to be published.

Authorship Contributions. All authors were involved in the critical revision of manuscript. Tao Chen and Qin Ning contributed to the study conception and design. Zhongwei Zhang, Ke Ma, Zhongyuan Yang, Qiuyu Cheng, Xue $\mathrm{Hu}$, Meiqi Liu, Yunhui Liu, Tingting Liu, Meng Zhang enrolled patients and collected clinical data. Zhongwei Zhang analyzed clinical data and drafted the manuscript. Xiaoping Luo had contributions to the revision of manuscript in discussion, data re-evaluation and presentation, and manuscript edition. All authors approved the final version of the manuscript, including the authorship list. 
Disclosures. Zhongwei Zhang, Ke Ma, Zhongyuan Yang, Qiuyu Cheng, Xue Hu, Meiqi Liu, Yunhui Liu, Tingting Liu, Meng Zhang, Xiaoping Luo, Tao Chen, Qin Ning have nothing to disclose.

Compliance with Ethics Guidelines. Patients in the prospective cohort were from the secondary study of a clinical trial (NCT03362632), and they were informed of the process of the study and gave consent for inclusion in the study (as well as the primary trial). Patients in the retrospective cohort were from our department of infectious disease, the informed consent was waived due to the nature of the retrospective study, but this study protocol was approved by the Ethics Committee of Tongji Hospital (TJ-C2017S321-2). Data of all patients were acquired from the electronic medical records system and analyzed anonymously according to the Declaration of Helsinki of 1975 , as revised in 2008 .

Data Availability. The datasets generated during and/or analyzed during the current study are available from the corresponding author on reasonable request.

Open Access. This article is licensed under a Creative Commons Attribution-NonCommercial 4.0 International License, which permits any non-commercial use, sharing, adaptation, distribution and reproduction in any medium or format, as long as you give appropriate credit to the original author(s) and the source, provide a link to the Creative Commons licence, and indicate if changes were made. The images or other third party material in this article are included in the article's Creative Commons licence, unless indicated otherwise in a credit line to the material. If material is not included in the article's Creative Commons licence and your intended use is not permitted by statutory regulation or exceeds the permitted use, you will need to obtain permission directly from the copyright holder. To view a copy of this licence, visit http://creativecommons.org/licenses/by$\mathrm{nc} / 4.0 /$.

\section{REFERENCES}

1. Bajaj JS, O'Leary JG, Wong F, et al. Bacterial infections in end-stage liver disease: current challenges and future directions. Gut. 2012;61(8):1219-25.

2. Fernández J, Acevedo J, Wiest R, et al. Bacterial and fungal infections in acute-on-chronic liver failure: prevalence, characteristics and impact on prognosis. Gut. 2018;67(10):1870-80.

3. Yang $\mathrm{L}, \mathrm{Wu} \mathrm{T}$, $\mathrm{Li} \mathrm{J}$, et al. Bacterial infections in acute-on-chronic liver failure. Semin Liver Dis. 2018;38(02):121-33.

4. Merli M, Lucidi C, Di Gregorio V, et al. An empirical broad spectrum antibiotic therapy in health-careassociated infections improves survival in patients with cirrhosis: a randomized trial. Hepatology. 2016;63(5):1632-9.

5. Karvellas CJ, Abraldes JG, Arabi YM, et al. Appropriate and timely antimicrobial therapy in cirrhotic patients with spontaneous bacterial peritonitis-associated septic shock: a retrospective cohort study. Aliment Pharmacol Ther. 2015;41(8):747-57.

6. Jalan R, Fernandez J, Wiest R, et al. Bacterial infections in cirrhosis: a position statement based on the EASL Special Conference 2013. J Hepatol. 2014;60(6):1310-24.

7. Moreau R. The pathogenesis of ACLF: the inflammatory response and immune function. Semin Liver Dis. 2016;36(02):133-40.

8. Lin S, Huang Z, Wang $M$, et al. Interleukin-6 as an early diagnostic marker for bacterial sepsis in patients with liver cirrhosis. J Crit Care. 2015;30(4): 732-8.

9. Reyes CS, García-Muñoz F, Reyes D, et al. Role of cytokines (interleukin-1 $\beta, 6,8$, tumour necrosis factor- $\alpha$, and soluble receptor of interleukin-2) and C-reactive protein in the diagnosis of neonatal sepsis. Acta Paediatr. 2007;92(2):221-7.

10. Wang H, Men P, Xiao Y, et al. Hepatitis B infection in the general population of China: a systematic review and meta-analysis. BMC Infect Dis. 2019;19(1):811.

11. Li Q, Wang J, Lu M, et al. Acute-on-chronic liver failure from chronic-hepatitis- $\mathrm{B}$, who is the behind scenes. Front Microbiol. 2020;11:583423.

12. Sarin SK, Kedarisetty CK, Abbas Z, et al. Acute-onchronic liver failure: consensus recommendations of the Asian Pacific Association for the Study of the Liver (APASL) 2014. Hepatol Int. 2014;8(4):453-71. 
13. Sarin SK, Kumar M, Lau GK, et al. Asian-Pacific clinical practice guidelines on the management of hepatitis B: a 2015 update. Hepatol Int. 2016;10(1): 1-98.

14. Amodio P. Hepatic encephalopathy: diagnosis and management. Liver Int. 2018;38(6):966-75.

15. Angeli P, Gines P, Wong F, et al. Diagnosis and management of acute kidney injury in patients with cirrhosis: revised consensus recommendations of the International Club of Ascites. Gut. 2015;64(4):531-7.

16. Jalan R, Saliba F, Pavesi M, et al. Development and validation of a prognostic score to predict mortality in patients with acute-on-chronic liver failure. J Hepatol. 2014;61(5):1038-47.

17. Angeli P, Bernardi M, Villanueva C, et al. EASL Clinical Practice Guidelines for the management of patients with decompensated cirrhosis. J Hepatol. 2018;69(2):406-60.

18. Mucke MM, Rumyantseva T, Mucke VT, et al. Bacterial infection-triggered acute-on-chronic liver failure is associated with increased mortality. Liver Int. 2018;38(4):645-53.

19. Choudhury A, Kumar M, Sharma BC, et al. Systemic inflammatory response syndrome in acute-onchronic liver failure: relevance of 'golden window': a prospective study. J Gastroenterol Hepatol. 2017;32(12):1989-97.

20. Katoonizadeh A, Laleman W, Verslype C, et al. Early features of acute-on-chronic alcoholic liver failure: a prospective cohort study. Gut. 2010;59(11): 1561-9.

21. Tornai T, Vitalis Z, Sipeki N, et al. Macrophage activation marker, soluble CD163, is an independent predictor of short-term mortality in patients with cirrhosis and bacterial infection. Liver Int. 2016;36(11):1628-38.

22. Papp M, Tornai T, Vitalis Z, et al. Presepsin teardown-pitfalls of biomarkers in the diagnosis and prognosis of bacterial infection in cirrhosis. World J Gastroenterol. 2016;22(41):9172-85.

23. Clària J, Arroyo V, Moreau R. The acute-on-chronic liver failure syndrome, or when the innate immune system goes astray. J Immunol. 2016;197(10): 3755-61.

24. Furst DE. Serum immunoglobulins and risk of infection: how low can you go? Semin Arthritis Rheum. 2009;39(1):18-29.

25. Sun Y, Huang T, Hammarström L, et al. The Immunoglobulins: new insights, implications, and applications. Annu Rev Anim Biosci. 2020;8(1): 145-69.

26. Papp M, Sipeki N, Vitalis Z, et al. High prevalence of IgA class anti-neutrophil cytoplasmic antibodies (ANCA) is associated with increased risk of bacterial infection in patients with cirrhosis. J Hepatol. 2013;59(3):457-66.

27. Schwabl P, Bucsics T, Soucek K, et al. Risk factors for development of spontaneous bacterial peritonitis and subsequent mortality in cirrhotic patients with ascites. Liver Int. 2015;35(9):2121-8.

28. Sargenti K, Prytz H, Strand A, et al. Healthcare-associated and nosocomial bacterial infections in cirrhosis: predictors and impact on outcome. Liver Int. 2015;35(2):391-400.

29. Fernandez J, Prado V, Trebicka J, et al. Multidrugresistant bacterial infections in patients with decompensated cirrhosis and with acute-onchronic liver failure in Europe. J Hepatol. 2019;70(3):398-411. 